\title{
Unreason and the liberal tradition Iain Brassington
}

\author{
Address: University of Manchester, Oxford Road, Manchester, UK \\ from WPA Thematic Conference. Coercive Treatment in Psychiatry: A Comprehensive Review \\ Dresden, Germany. 6-8 June 2007 \\ Published: 19 December 2007 \\ BMC Psychiatry 2007, 7(Suppl I):S2I doi:I0.1 186/I47I-244X-7-SI-S2I
}

This abstract is available from: http://www.biomedcentral.com/ I 47I-244X/7/SI/S2 I

(C) 2007 Brassington; licensee BioMed Central Ltd.

It is conventionally thought impermissible to force treatment on a patient, even when his life is at stake. Following Kant or Mill, we may defend this convention either by appealing to the inviolability of autonomy, or to the benefits of treating liberty as inviolable, subject only to considerations of harm to others. In both cases, an exception might be made for mental illness. For Kant, autonomy is not unconstrained; because it is inseparable from reason, it must conform to rational norms and can be discerned by conformity thereto. A refusal of treatment that derives from a mental illness is ex hypothesi non-rational, therefore heteronomous, and can therefore be overridden without undermining autonomy. By contrast, the liberal tradition in which Mill writes, echoing Hobbes, understands liberty simply as the absence of constraint. In this picture, we cannot assume that unreason undermines liberty. But this raises a question concerning the permissibility of beneficent but unconsented interventions to treat mental illness. For sure, Mill's defence of liberty does not extend to those incapable of self-government, so might allow beneficent but unconsented interventions to treat at least some cases of mental illness. Still, there is no reason to suppose that the mentally ill lack the intelligence or information necessary for liberty, so if liberty is simply the absence of constraint, such interventions would have to rely on the idea that there is some other difference between irrational-but-sane and irrational-but-insane actions such as to mean that the former are compatible with liberty but the latter are not. It is not easy to give an account of this difference without begging the question or smuggling in norms from another tradition. The upshot is that it is hard for the liberal tradition to keep hold of the right to make foolhardy decisions while also allowing for beneficent but unconsented treatment in cases of mental illness. 